\title{
Is Brucella an enteric pathogen? Reply from Tsolis, Solnick and Baümler
}

\author{
Renée M. Tsolis, Jay V. Solnick and Andreas J. Bäumler
}

We discuss below the correspondence on our Review article (From bench to bedside: stealth of enteroinvasive pathogens. Nature Rev. Microbiol. 6, 883-892 (2008)) $)^{1}$, by Gorvel, Moreno and Moriyón (Is Brucella an enteric pathogen? Nature Rev. Microbiol. 27 Jan 2009 (doi:10.1038/nrmicro2012-c1)) ${ }^{2}$. The authors elegantly point out the "marked structural, physiological and phylogenetic differences between" Brucella spp. and Salmonella enterica subsp. enterica serovar Typhi "that set a clear distinction in their pathobiology". We agree with this observation. In fact, the starting point of our inquiry was the puzzling observation that $S$. Typhi is more closely genetically related to Salmonella enterica subsp. enterica serovar Typhimurium than it is to Brucella spp., but yet the clinical presentations of typhoid fever and human brucellosis are more similar to each other than to human gastroenteritis. For example, $S$. Typhimurium-induced gastroenteritis manifests as diarrhoea and vomiting within 48 hours of infection ${ }^{3}$. By contrast, the median incubation period for typhoid fever is 2 weeks, which is similar to the $2-4$ week incubation period for brucellosis ${ }^{4,5}$.
This suggests that there is an initial evasion of innate host responses, and patients with both infections frequently present with constipation $^{6,7}$. A recent study found that owing to the similar clinical presentation of human infections with $S$. Typhi and Brucella species, more than half of brucellosis cases in Egypt were misdiagnosed as typhoid fever ${ }^{8}$, which shows that both of these pathogens are associated with the same human disease syndrome (although, arguably, 'enteric fever' might not be the best designation for it).

The point of our article was to shed light on why host responses are often similar and characteristic for groups of pathogens that are genetically different, as for S. Typhi and Brucella species. A possible explanation offered in our review was that S. Typhi and Brucella spp., although different in many aspects of their biology, use similar strategies to conceal their identity from the innate immune system, which makes it difficult for the host to identify them as bacterial pathogens and mount an appropriate antibacterial response. We agree that there is uncertainty as to which area (or areas) of the gastrointestinal tract is invaded by Brucella spp. after the organisms are ingested, which is the most common route for human infection ${ }^{9}$. Nevertheless, although Brucella spp. and $S$. Typhi can invade different areas of the mucosa in the gastrointestinal tract, both pathogens subsequently seem to use similar virulence strategies to attenuate neutrophil recruitment to the site of invasion, a factor that probably facilitates their systemic dissemination.
Renée M. Tsolis, Jay V. Solnick and Andreas J. Bäumler are at the Department of Medical Microbiology and Immunology, School of Medicine, University of California at Davis, One Shields Avenue, Davis, 95616 California, USA. Correspondence to A.J.B e-mail:ajbaumler@ucdavis.edu

1. Tsolis, R. M., Young, G. M., Solnick, J. V. \& Baumler, A. J. From bench to bedside: stealth of enteroinvasive pathogens. Nature Rev. Microbiol. 6, 883-892 (2008).

2. Gorvel, J. P., Moreno, E. ¿ Moriyôn, I. Is Brucella an enteric pathogen? Nature Rev. Microbiol. 27 Jan 2009 (doi: 10.1038/nrmicro2012-c1).

3. Miller, S. I. \& Pegues, D. A. in Principles and Practice of Infectious Diseases (eds Mandell, G. L., Bennett, J. E. \& Dolin, R.) 2344-2363 (Churchill Livingstone, Philadelphia, 2000)

4. Olsen, S. J. et al. Outbreaks of typhoid fever in the United States, 1960-99. Epidemiol. Infect. 130, 13-21 (2003)

5. Young, E. J. in Principles and Practice of Infectious Diseases (eds Mandell, G. L., Bennett, J. E. \& Dolin, R.) 2386-2393 (Churchill Livingstone, Philadelphia, 2000)

6. Butler, T., Islam, A., Kabir, I. \& Jones, P. K. Patterns of morbidity and mortality in typhoid fever dependent on age and gender: review of 552 hospitalized patients with diarrhea. Rev. Infect. Dis. 13, 85-90 (1991).

7. Madkour, M. M. in Madkour's Brucellosis (ed. Madkour, M. M.) 150-157 (Springer-Verlag, Heidelberg, 2001).

8. Jennings, G. J. et al. Brucellosis as a cause of acute febrile illness in Egypt. Trans. R. Soc. Trop. Med. Hyg. 101, 707-713 (2007).

9. Pappas, G., Akritidis, N., Bosilkovski, M. \& Tsianos, E. Brucellosis. N. Engl. J. Med. 352, 2325-2336 (2005). 